\title{
Building capacity and social capital around interpretive research quality
}

\section{Dr. Joachim Walther, University of Georgia}

Dr. Walther is an assistant professor of engineering education research at the University of Georgia (UGA). He is the director of the Collaborative Lounge for Understanding Society and Technology through Educational Research (CLUSTER), an interdisciplinary research group with members from engineering, art, educational psychology, and social work.

His research interests range from the role of empathy in engineering students' professional formation, the role of reflection in engineering learning, and interpretive research methodologies in the emerging field of engineering education research.

His teaching focuses on innovative approaches to introducing systems thinking and creativity into the environmental engineering program at the University of Georgia.

\section{Dr. Nicola Sochacka, University of Georgia}

Dr. Nicki Sochacka received her doctorate in Engineering Epistemologies from the University of Queensland, Australia, in 2011. She is currently a member of the CLUSTER research group at the University of Georgia where she holds a research and teaching position. Nicki's areas of research interest include: STEAM (STEM + Art) education, diversity, interpretive research quality, the role of empathy in engineering education and practice, and student reflection. 


\title{
Building capacity and social capital around interpretive research quality
}

\begin{abstract}
Set in the context of an NSF-funded CAREER project, this paper describes a collaborative effort in the engineering education research community to build social capital and capacity around questions of research quality. To date, this effort has entailed: i) two one and a half-day longitudinal interactive workshops with leading qualitative researchers in the field of engineering education and their graduate students (2013, $\mathrm{n}=9$ faculty, $\mathrm{n}=8$ graduate students; $2014, \mathrm{n}=8$ faculty, $n=10$ graduate students), and ii) three broader participation workshops at national and international engineering education conferences (AAEE 2012, $\mathrm{n}=16$; ASEE 2013, $\mathrm{n}=112$; FIE $2014, \mathrm{n}=18$ ). This paper describes the model of the ongoing collaborative engagement process, summarizes findings and insights concerning research quality, and outlines plans for future work.
\end{abstract}

\section{Introduction}

The long-term goal of the research program initiated by this NSF-funded CAREER project is to cultivate, catalyze, and systemize a much needed theoretical discourse within the engineering education research community around research quality in qualitative, or "interpretive", approaches. The need for and timeliness of this work rests on the following three observations of the emerging, interdisciplinary field of engineering education research:

- The field of engineering education is embracing an ever broader range of interpretive methods of inquiry ${ }^{[1 ; 2 ; 3 ; 4 ; 5 ; 6]}$. This epistemological and methodological diversity has stimulated a debate around what constitutes rigorous research, that is, acceptable ways of conducting and assessing research ${ }^{[2 ; 7 ; 8 ; 9 ; 10 ; 11]}$. At the same time, a crucial body of qualitative work is emerging through the increased adoption of qualitative methods ${ }^{[4 ; 6}$; ${ }^{12]}$ and recent NSF funding efforts, particularly in the Research in Engineering Education (REE) program and engineering education CAREER awards.

- There is a lack of a consensus concerning ways of conceptualizing quality in interpretive research in part due to the fact that fundamental assumptions underlying interpretive research are often unfamiliar to researchers from traditional engineering backgrounds ${ }^{[2]}$. Also, fields that more commonly employ interpretive approaches provide no broad consensus on the issue of research quality ${ }^{[13]}$. And,

- There is a recognized need for theory and evidence-based frameworks $[11 ; 14 ; 15 ; 16 ; 17 ; 18]$ that provide context- and discipline-specific approaches for engineering education research to move beyond contextual application of individual research methods ${ }^{[5 ; 17]}$.

With these characteristics of the field of engineering education research in mind, the goal at the outset of this project was to build on an initial theoretical understanding of research quality with the view to developing a quality framework that reflects the practices of engineering education researchers. This goal was to be achieved through two streams (see below) of integrated data gathering and educational workshops and the qualitative analysis of the data using iterative coding methods of constant comparison ${ }^{[19 ; 20 ; 21 ; 22 ; 23]}$. 
- Stream A: In-depth longitudinal workshops targeting engineering education researchers with a demonstrated interest and developing expertise in interpretive research methods.

- University of Georgia, Athens, Georgia, June 21-22, $2013(\mathrm{n}=9$ faculty, $\mathrm{n}=8$ graduate students)

- Purdue University, West Lafayette, Indiana, June 13-14, 2014 ( $\mathrm{n}=8$ faculty, $\mathrm{n}=$ 10 graduate students)

- Stream B: Broad participation workshops targeting a broad and diverse range of participants within the engineering education community.

- Australasian Association of Engineering Education (AAEE) Annual Conference, Swinburne University, Melbourne, Australia, December 2, 2012 ( $n=16)$

- American Society for Engineering Education (ASEE) Annual Conference, Atlanta, Georgia, June 24, $2013(n=112)$

- Frontiers in Education (FIE) Annual Conference, Madrid, Spain, October 21 ( $\mathrm{n}=$ 18)

After the first longitudinal workshop, however, it became clear that the two dimensions of the initial proposal: a) the process model, and b) the four validation constructs (Theoretical, Procedural, Communicative and Pragmatic Validation) and Process Reliability, resonated with the participants and helped them to situate and work with quality challenges in the context of their own projects. For this reason, it was decided to adapt the data gathering and analysis focus of the project and workshop from a researcher-researched model to a collaborative inquiry-based approach $^{[24 ; 25 ; 26 ; 27 ; 28]}$. This shift has led to a number of on-going collaborative activities, two of which are described in more detail below.

\section{"Multiple voices" paper}

Building on the momentum from the first longitudinal workshop, it was decided to pursue a "multiple voices" paper, which six out of the nine faculty participants at the workshop committed to contributing to ${ }^{[29]}$. This process, which is still ongoing, has led to a deeper and more nuanced understanding of the initial proposed quality framework, with a particular focus on interactions between the different aspects of validation and Process Reliability, as well as a better understanding of possible misconceptions of the categories. It is also in the context of working on this collaborative effort that a "question-based" format of the quality framework was developed to inform quality planning activities ${ }^{[30]}$. More specifically, this shared project and eventual publication will serve to:

- Provide a deeper, pragmatic insight into the overall framework and its theoretical components;

- Offer a set of worked examples intended to stimulate the further, flexible adoption of the framework and/or to serve as a teaching resource for emerging cohorts of engineering education graduate students pursuing qualitative research;

- Expand the framework to, and demonstrate its use in, other interpretive studies based on different methodological perspectives compared to the original example study; and,

- Critically examine how the framework was used in these studies to explore, plan, implement, reflect on, document, and demonstrate research quality. 


\section{Ethical validation as a sixth validation construct and core aspect of research quality}

Based on conversations at the first longitudinal workshop, over the past two years the authors have collaborated with Dr. Alice Pawley from Purdue University to pursue the idea of ethical validation as an additional, sixth dimension of the quality framework. These explorations were prompted by the recognition in our own work that: i) ethical considerations extend beyond institutional review processes of early project plans and concern the entire research process, and ii) crucial aspects of the human experience of researchers and researched are commonly not considered in the context of research methodology ${ }^{[31]}$. At the same time, we propose that ethical issues, considerations, and practices lie at the heart of the integrity, trustworthiness, and robustness of interpretive research and are thus a key aspect of overall quality considerations. We have explored this issue through a community of practice approach that has comprised regular conversations about our concrete research practice anchored in discussions of the broader literature about ethical aspects of qualitative research.

\section{Future work}

In furthering the collaborative inquiry approach to articulate and theoretically frame quality conceptions and practices within the engineering education research community, we are currently also pursuing the following three initiatives:

New meanings of old strategies - exploring existing quality strategies through the Quality Framework

At several points during the workshops, the quality framework was used to explore some of the quality strategies described in the literature that engineering education researchers use in their projects (e.g. triangulation, purposive sampling, etc.). The workshop participants found that the quality framework allowed them to both fundamentally understand the specific contribution of a particular strategy to overall quality and to explore the role of a quality strategy in the context of their own research projects. The purpose of this initiative is to explore a number of such strategies, from a range of methodological perspectives, and to 'de-mystify' their role in engineering education research. This collaborative exploration will be based on research experiences from members of the group with the aim to provide novice researchers with a sense of the use of such strategies in a specific engineering education context.

Coding journals, memos and log trails: Diverse practices and benefits from a quality perspective One key question explored at the workshop was how the quality framework and associated ways of thinking can be 'operationalized' in diverse engineering education research projects. One promising starting point was a range of conversations about the use of coding journals, memos or $\log$ trails to support a range of interconnected quality aspects. The focus of this collaborative exploration is to explore diverse practices of keeping and using such research records and to examine their context-specific contribution to procedural validation, communicative validation, and process reliability.

Using the Quality Framework as a lens to explore issues of research quality in phenomenographic engineering education research

A number of conversations at the workshop explored questions of research quality from the methodological perspective of phenomenography. Participants felt that the quality framework 
provides a useful lens to ground these discussions and make a methodological contribution to this emerging research methodology. There seemed to be a consensus that a certain degree of uncertainty around using and justifying this methodology, as well as articulating research choices, prevails in the community. Given this need and a critical mass of participants interested in this research tradition, a contribution in this area was determined by group to be promising and timely.

\section{Conclusion}

This paper has described efforts to engage the engineering education research community around questions of interpretive research quality. Set in the context of an NSF-funded CAREER project, the paper first outlined the rationale underlying these efforts, as well as the specific actions taken thus far, and ongoing shared projects. Together, the interactive workshops and on-going collaborative investigations have served to catalyze a vibrant discourse related to issues of interpretive research quality that is both grounded in the literature and in concrete research practice. We offer this model of community engagement and inquiry as an exemplar to the engineering education research community as we work towards establishing our own contextspecific research paradigm.

\section{Acknowledgements}

This material is based upon work supported by the National Science Foundation under Grant No. 1150668. Any opinions, findings, and conclusions or recommendations expressed in this material are those of the authors and do not necessarily reflect the views of the National Science

Foundation.

\section{References}

1. Baillie, Caroline, Ko, Edmond, Newstetter, Wendy, \& Radcliffe, David F. (2011). Advancing Diverse and Inclusive Engineering Education Practices through Interdisciplinary Research and Scholarship. Journal of Engineering Education, 100(1), 6-13.

2. Borrego, Maura. (2007). Conceptual Difficulties Experienced by Trained Engineers Learning Educational Research Methods. Journal of Engineering Education, 96(2), 91.

3. Borrego, Maura. (2007). Development of Engineering Education as a Rigorous Discipline: A Study of the Publication Patterns of Four Coalitions. Journal of Engineering Education, 96(1), 5-18.

4. Borrego, Maura, Douglas, Elliot P., \& Amelink, Catherine T. (2009). Quantitative, Qualitative, and Mixed Research Methods in Engineering Education. Journal of Engineering Education, 98(1), 53-66.

5. Case, Jennifer M., \& Light, Gregory. (2011). Emerging Research Methodologies in Engineering Education Research. Journal of Engineering Education, 100(1), 186-210.

6. Koro-Ljungberg, Mirka, \& Douglas, Elliot P. (2008). State of Qualitative Research in Engineering Education: Meta-Analysis of JEE Articles, 2005-2006. Journal of Engineering Education, 97(2), 163-174.

7. Fortenberry, Norman L. (2006). An Extensive Agenda for Engineering Education Research. Journal of Engineering Education, 95(1), 3.

8. Journal of Engineering Education. (2006). The Research Agenda for the New Discipline of Engineering Education. Journal of Engineering Education, 95(4), 259.

9. Leydens, Jon A, Moskal, Barbara M, \& Pavelich, Michael J. (2004). Qualitative Methods Used in the Assessment of Engineering Education. Journal of Engineering Education, 93(1), 65.

10. Moskal, Barbara M, Leydens, Jon A, \& Pavelich, Michael J. (2002). Validity, reliability and the assessment of engineering education. Journal of Engineering Education, 91(3), 351. 
11. Streveler, Ruth A, \& Smith, Karl A. (2006). Conducting Rigorous Research in Engineering Education. Journal of Engineering Education, 95(2), 103.

12. Douglas, E. P., Koro-Ljungberg, M., \& Borrego, M. (2010). Challenges and Promises of Overcoming Epistemological Partiality: Advancing Engineering Education Through Acceptance of Diverse Ways of Knowing. European Journal of Engineering Education, 35(3), 247 - 257.

13. Flick, Uwe. (2006). An introduction to qualitative research (3rd ed.). London: Sage Publications.

14. Jamieson, Leah H., \& Lohmann, Jack. (2009). Creating a culture for scholarly and systematic innovation in engineering education. Phase 1 report.

15. Kemnitzer, S. . (2008). The need for theory-based research in engineering education. Video interview recorded at ASEE 2008. from CASEE video channel on YouTube: http://www.youtube.com/watch?v=nfsh08jHEKs

16. Shulman, Lee S. (2005). If Not Now, When? The Timeliness of Scholarship of the Education of Engineers. Journal of Engineering Education, 94(1), 11.

17. Johri, A. (2010). Creating Theoretical Insights in Engineering Education. Journal of Engineering Education, 99(3), 183.

18. Watson, K. (2009). Change in Engineering Education: Where Does Research Fit? Journal of Engineering Education, 98(1), 3.

19. Creswell, John W. (1998). Qualitative inquiry and research design: Choosing among five traditions. Thousand Oaks, Calif.: Sage Publications.

20. Creswell, John W. (2009). Research design: qualitative, quantitative, and mixed methods approaches. Thousand Oaks: Sage Publications.

21. Denzin, N.K., \& Lincoln, Y.S. (2011). The SAGE Handbook of Qualitative Research: SAGE Publications.

22. Glaser, B. J. (1969). The constant Comparative Method of Qualitative Research. In G. J. McCall \& J. L. Simmons (Eds.), Issues in participant observation: a text and reader. Reading, Mass.: Addison-Wesley Pub. Co.

23. Hatch, J. Amos. (2002). Doing qualitative research in education settings. Albany, N.Y.: State University of New York Press.

24. Bray, John N. (2000). Collaborative Inquiry in Practice: Action, Reflection, and Making Meaning: SAGE Publications.

25. Heron, John, \& Reason, Peter. (1997). A Participatory Inquiry Paradigm. Qualitative Inquiry, 3, 274-294. doi: $10.1177 / 107780049700300302$

26. Kasl, Elizabeth, \& Yorks, Lyle. (2002). Collaborative Inquiry for Adult Learning. New Directions for Adult \& Continuing Education, 2002(94), 3-11.

27. Love, N. (2008). Using Data to Improve Learning for All: A Collaborative Inquiry Approach: SAGE Publications.

28. Reason, P., \& Bradbury, H. (2007). The SAGE Handbook of Action Research: Participative Inquiry and Practice: SAGE Publications.

29. Walther, Joachim, Sochacka, Nicola W, Pawley, Alice L., Phillips, Canek, Douglas, Elliot, Bumbaco, Amy, ... Kellam, Nadia N. (in preparation). Qualitative Research Quality: Practice explorations from multiple methodological perspectives. Journal of Engineering Education.

30. Walther, Joachim, \& Sochacka, Nicola W. (2014). Qualifying Qualitative Research Quality (The Q3 Project) - An interactive discourse around research quality in interpretive approaches to engineering education research. Paper presented at the Frontiers in Engineering Education Conference, Madrid, Spain.

31. Walther, Joachim, Pawley, Alice L., \& Sochacka, Nicola W. (in preparation). Exploring Ethical Validation as a Key Consideration in Interpretive Research Quality. Paper presented at the American Society for Engineering Education Annual Conference, Seattle, WA. 